\title{
WINDSTORM COVERAGE IN JAPAN
}

\author{
Masao Wakuri
}

Japan is not only a well-known earthquake prone country, but also a land very liable to damage by windstorm, flood, tidal wave and highwater. Especially, it is visited every year by typhoons or tropical cyclones. These occur during the period from early summer to autumn with accompanying heavy rains, and severe damage is often suffered. Most of the serious disasters result from the following causes.

a) Flood from a rapid small river in mountainous areas or landslide occurring there.

b) Innundation of a large plain area caused by the collapse of embankments following heavy rain.

c) Highwater or tidal wave in a harbour or a bay, which is often caused by the visit of a typhoon particularly at full tide.

Generally speaking, damage by the wind is much less in severity than that by flood, tidal wave or highwater.

These natural calamities occur every year, but the extent of the damage differs greatly from year to year. Taking an example of the damage to buildings and contents during Io years from 1965 to 1974 , the largest annual damage estimated for the whole country was $¥$ I6r.875 million (approx. U.S. $\$ 578$ million), the smallest $¥ 9.398$ million (approx. U.S. $\$ 33,6$ million) and the average $¥ 58.56 \mathrm{r}$ million (approx. U.S. $\$ 209$ million). (These are the original figures not adjusted for inflation. Also, they do not include the damage to outdoor objects such as roads, bridges, railways, communication facilities, electricity facilities and farms). The greatest windstorm damage in recent years was brought about by the "Bay of Ise Typhoon" in September 1959, at which 53.893 buildings were lost or seriously damaged, 5 .IOI persons were killed or went missing and 2.430 ships were lost.

Districts liable to suffer from these natural calamities are known beforehand. The densely built-up areas below the sea level in Tokyo, 
Osaka and Nagoya (including their vicinities) are feared to suffer serious damage in the case of highwater. Danger is also forecast for the areas around those small rivers in mountainous regions where a sudden and extraordinary swell of water is seen following heavy rains. For the other example of dangerous objects, we can mention the buildings situated on a steep slope or at the foot of a precipice.

Windstorm cover written by insurance companies is divided into three types. One is the cover included in comprehensive policies such as householders' comprehensive, another is extended coverage endorsement to fire policies and the other is windstorm insurance as an independent cover. The former is granted for dwelling and commercial risks and the latter two mainly for industrial risks. The windstorm cover by comprehensive policies is fairly spread among the policyholders as it is non-optionally included in the policy, but this is only a limited cover subject to $30 \%$ franchise, indemnity ratio of $30 \%$ (only $30 \%$ of the estimated loss being covered) and the maximum indemnity is $¥ 2.400,000$ for buildings and $¥_{1,500,000}$ for contents. The other two types of cover are in principle not subject to such indemnity limitations, but insurers are careful in their underwriting to avoid adverse selection by the policyholders which is incidental to these sorts of protection. It must be added that windstorm is covered by marine and aviation insurances without any limitations and that heavy claims sometimes occur due to typhoon damage on the accumulated risks in harbour areas written under marine policies.

The amount of claims having been paid for windstorm damage is not estimated exactly enough, but it is known that, during 7 years from 1967 to 1973 , the largest annual loss in the non-marine field was about $¥$ I.800 million (U.S. $\$ 6,4$ million), the smallest about $¥ 44$ million (U.S. $\$ 157.000$ ) and the average about $¥ 490$ million (U.S. $\$ 1,75$ million). The annual claims amount fluctuates greatly, but it shows a tendency to increase with the growing volume of the business, and this latter factor is indicated by the fact that the premium income for both windstorm extention to fire insurance and independent windstorm insurance more than doubled during these 7 years. It should also be noted that, under comprehensive policies, a very limited cover was given during this period, but the 
cover was expanded to the beforementioned level in 1975, resulting in the corresponding increase in the claims amount.

Windstorm cover is granted not only by insurance companies under the aforesaid plan but also by some cooperative societies, whose policies are referred to in Japan as "mutual relief" contracts. One of the most influential of these societies, the National Mutual Insurance Federation of Agricultural Cooperatives, includes a cover for natural calamities in their most usual fire insurance policies. This cover is granted subject to $5 \%$ franchise and indemnity ratio of $30 \%$ (50\% in case of a total loss). However, there is no special fixed limits to indemnity to be applied solely for these perils.

Perhaps we could say that, in general, insurance companies have been more prudent in covering windstorm risk than cooperative societies. One of the reasons for this is presumed to be the fact that the companies include many objects situated in the densely builtup areas in lowlands under fire and comprehensive insurances. Insurance companies are facing, however, increasing demand from the general society for expanding windstorm cover as a means of protecting the general public. In compliance with this demand, they have gradually expanded the windstorm cover under comprehensive policies of various kinds, and this expansion is expected to continue in the future.

With the comprehensive insurances, the risk premium rate for windstorm is fixed irrespective of the location or building construction. This contributes to the simple structure of the comprehensive insurance premiums, which consists of the ordinary fire premiums according to the risk situations and of the fixed rate of loading for the additional perils, and which aims at easy handling of the policies. Insurers have been able to apply this simple system since only a small portion of the total risk premium has been appropriated to windstorm because of the limitations to the indemnity. For the future, however, a problem could occur of whether this fixed rate system will remain justifiable when the windstorm cover is further expanded. With the windstorm extention to ordinary fire insurance and independent windstorm insurance, premiums are arrived at individually according to the actual risk situation, for which detailed research is made of the distance from the seashore or the riverside, conditions of the embankments, height of the location of the prop- 
erty above the water or sea level, construction of the building, damageability of the contents, and other factors.

The greatest difficulty that may confront us with the probable future expansion of windstorm cover will be the uneven distribution of the hazard. Of the policyholders of fire and comprehensive insurances, rather few are living in the districts with an enormous hazard of flood, tidal wave or high water, whereas the remaining majority are not requiring much attention for these risks. In view of such differences in the hazard, it could be considered unfair and harmful to policyholders to continue this fixed rate system, if we assume that windstorm risk premiums should be increased with the expansion of the cover. On the other hand, however, if the premiums are charged according to the individual risk situation, the burden will be too heavy for the policyholders in the hazardous areas to bear, whereas it will be almost negligible for those in the less hazardous areas. This would not only be contrary to the socialpolitic objectives which motivate the expansion of this cover, but also be fatal to the existence of this protection as an insurance business. This remains to be a problem for the insurers to solve in the future. 